\title{
Mastery of Basic Addition and Subtraction Facts: How Much and What Kind of Drill, at What Time is Sensible?
}

\author{
Michael Gaidoschik \\ Free University of Bozen - Bolzano, Italy
}

This case study reports on two Austrian first-grade teachers who centered their teaching of basic addition and subtraction on derived fact strategies. The teachers differed distinctly in their handling of drill. Only one of them made considerable efforts at drilling strategies. In her class, at the end of grade one, there was a high share of fact retrieval even with sums and minuends greater than 10. Conversely, in the other class, more students used derived facts strategies, and some of them repeatedly performed at low speed. While students in both classes demonstrated a sound understanding of strategies, the emphasis on drill in one class might have had negative consequences on one child's motivation. Possible consequences for future research are discussed.

Keywords: Basic addition and subtraction, derived fact strategies, fact mastery, automaticity, strategy drill.

In the current literature on mathematics education there is widespread agreement that eventually pupils should solve the basic addition and subtraction facts up to 20 without using counting strategies (cf., e.g., Gerster, 2009; Van de Walle, 2004). However, there is fewer consensus when it comes down to defining more differentiated target sets. First, there is the issue of what precisely the teaching of basic addition and subtraction should strive. Should strictly immediate retrieval of all basic facts be the goal, or does sufficient fact mastery also include "derived fact strategies" (Dowker, 2014; Steinberg, 1985)? Such strategies also referred to as "reasoning strategies" (Baroody, Purpura, Eiland, Reid, \& Paliwal, 2015) build upon relations between facts. Using a derived fact strategy (DFS), a child who already knows $6+6=12$ could solve, e.g., $6+7$ by adding one.

Scholars such as Van de Walle (2004) or Gerster (2009) clearly advocate the consideration of quick ("in about 3 seconds", Van de Walle, 2004, p. 156), effortless and correct use of such strategies as part of fact mastery. However, other scholars insist on the importance of actually knowing by heart at least the number combinations up to 10 (Schipper, 2009). The Common Core State Standards of Mathematics (CCSSM) even formulate the clear expectation that "by end of grade 2" pupils should "know from memory all sums of two one- 

in what ways they should integrate drill into their teaching of basic facts. As a starting point for considerations for future research, this paper contributes case studies of two Austrian teachers and their respective classes who, as will be documented, represent two considerably different ways of dealing with drill within a teaching approach focused on conceptual understanding.

The two teachers had attended the same professional teacher development program. A main target of this program had been to convey upto-date didactical recommendations for teaching arithmetic in grade 1. As a basis for understanding what might actually have happened in the two classrooms, the paper will first give a short outline of the program. Second, the study reports on common features and differences of the instructional measures the two teachers had presumably set throughout the school year. Against this background, the study addresses mainly the following questions:

a) Having received comparable targeted instruction on DFS, yet combined with a distinctly different amount of drill, to what extent do children in two classes at the end of their first school year demonstrate fact mastery on basic addition and subtraction tasks?

b) Are there any indications for qualitative connections between differing classroom practices regarding drill and children's calculation strategies and attitudes towards arithmetic?

\section{Methods}

\section{Participating Children}

This case study reports on two first-grade teachers and their respective classes from different public primary schools in Carinthia, Austria. Class A, situated in a small village, included 23 pupils. Only 17 of them were regular first-graders ( 6 to 7 years old), and only 11 of these ( 8 boys, 3 girls) took part in the study, due to the reservations of some parents who did not want their children interviewed. Twenty-one pupils, 17 of them regular first-graders, attended Class B, an urban class with a mixed catchment area. Parents gave consent to interview 16 pupils ( 7 boys, 9 girls).

\section{Participating Teachers}

Both teachers had participated in a teacher development program that a group of expert teachers had implemented independently from the study author (for details, cf. Gaidoschik et al., 2017). The program had started in 2012/2013 with two three-hour input sessions devoted to first-grade arithmetic, regarded by the program's leader only as a "teaser" to arouse interest in the subject (cf. Gaidoschik et al., 2017). The actual training happened in 2013/2014, while the teachers were teaching Class A and B, respectively. Throughout this year, both teachers were getting support from an expert teacher, who visited their schools for two hours each week. During each visit, these mentors spent one hour with their mentees outside the classroom on the planning and developing of lessons. 

working on the helping facts, students got lists of the same few tasks they were supposed to practice at home with their parents' assistance. As soon as they themselves felt ready to solve these tasks by quick retrieval, they should volunteer for an oral exam. Later on, following the treatment of a single derivation strategy such as "near doubles" in the classroom, tasks such as $6+7$ or $8+7$ that could be derived by using that very strategy were put together on yet another list. Again, children should train these tasks at home as well as in daily five-minute classroom exercises.

Finally, in the last months of the school year, Teacher A established a daily individual classroom practice involving a CD-ROM. Her students used a training mode requiring them to solve tasks up to 20 as quickly as they could. Teacher A periodically examined their progress. When they finally had reached the expected speed level, she rewarded them with a diploma.

Teacher A left no doubt that by spending that high amount of time and energy on drill she followed her own conviction that "knowing these tasks by heart in the second grade is very important for [the children]". She declared that she had not learnt this from the program.

Teacher B, by contrast, expressed skepticism over drill measures of any kind. She repeatedly emphasized that she did not want pupils to learn by heart anything they had not thoroughly understood: "I think it's more important to know how to figure it out than to answer quickly as a shot." She herself strongly objected to qualifying any of her classroom routines as drill, even if she made clear that her students, too, had spent a substantial part of the first half-year on practicing the helping facts. Unlike Teacher A, however, she had never expected or asked parents to engage heavily in that matter. With regard to fluency, she substantially relied on daily classroom conferences on DFS and having students repeatedly describe their solving pathways. She was confident that students, once they had understood the strategies and acquired routine in using them, eventually would reach automaticity in all the basic facts anyway. Consequently, in Class B, strategy drill played a minor role, if any.

\section{Methods Used to Establish Children's Solution Strategies}

The study author interviewed the children in a quiet room separated from the classroom during school time two weeks before the end of the school year. All interviews were videotaped. The children solved 14 addition and subtraction tasks up to ten and 8 tasks with sums and minuends between eleven and eighteen. Tasks were presented one by one both verbally and simultaneously as written on a flash card; children were asked to solve each task mentally in the way they usually would, and state the result verbally. Immediately thereafter, they should explain or show how they had arrived at the solution.

Two additional tasks were used to examine children's conceptual understanding of DFS apart from their computing performance. The child was shown, at the end of each interview, two pairs of terms, each of which printed 
on a DIN-A7 card, first 7+7 and 7+8, second $9+9$ and $18-9$. The child was asked not to compute, but to tell whether the first task of each pair could be of help for solving the second one, and if so, in what way.

\section{Evaluation Procedure}

Coding of the children's computing strategies was based on their verbal reports, also taking into account gestures, facial expressions and solving time as possible indicators of counting strategies. A fellow researcher doublechecked ten percent of the ratings, randomly selected. Disagreements were very few and resolved through discussion.

Out of the various strategies that are described in the research literature to be applied by children of this age group (cf. Gaidoschik, 2012), the pupils of both classes essentially used but two, namely either fact retrieval or a DFS (see Table 1). A pragmatic approach was taken when considering the difficulty to discern whether a child has spontaneously retrieved a known fact from memory or quickly applied a DFS (Verschaffel, Greer, \& De Corte, 2007). The main interest of the study is not on fact retrieval, but fact mastery as defined by Van de Walle (2004) as "giving a quick response (in about 3 seconds) without resorting to non-efficient means such as counting" (p. 156). Obviously, this includes both fact retrieval and DFS.

Therefore, a strategy was rated as "presumably retrieved" whenever a child produced a correct answer spontaneously stating that he or she "just knew it". This concedes the possibility that the child might in fact have derived the answer very quickly.

Whenever there was an at least short hesitation before the child produced the answer, but no indication of overt or mental counting, and the child described a task-fitting DFS as his or her solution path thereafter, the strategy was rated as "presumably derived". This leaves open the possibility that the child might in fact have retrieved the answer, yet with some delay, and put forward a reasoning strategy just because s/he believed that $\mathrm{s} / \mathrm{he}$ was supposed to justify the answer. In any case, the time needed to produce a solution was taken, allowing for the attribution of "fact mastery" to all cases when a child answered correctly in about 3 seconds or less.

\section{Results}

\section{Extent of Fact Mastery in Classes A and B}

During the interviews with Class A, there were 242 instances of task solving up to 20 ( 22 tasks by each of the eleven students). Counting on from larger was observed in one single instance, as was the non-counting use of finger-patterns (cf. Gaidoschik, 2012). Apart from that, all trials were rated as either (presumably) retrieved or derived. Children missed the right answer in only three instances. 
The 16 students of Class B did not use counting strategies at all, but fingers were employed without counting in three cases. Class B students either retrieved or derived all other tasks, producing erroneous results in only two cases.

As can be seen in Table 1, there were striking differences regarding the respective shares of tasks that children in Class A and B (presumably; see above) retrieved or derived, as well as regarding the extent of fact mastery in both classes as defined by their solution times.

\section{Table 1}

Frequency of presumably retrieved and derived solutions and of fact mastery in Classes A and B

\begin{tabular}{ccccccc}
\hline & \multicolumn{3}{c}{ sums/minuends smaller than 10} & \multicolumn{3}{c}{ sums/minuends greater than 10} \\
\hline & retrieved & derived & $\begin{array}{c}\text { fact } \\
\text { mastery }\end{array}$ & retrieved & derived & $\begin{array}{c}\text { fact } \\
\text { mastery }\end{array}$ \\
$\begin{array}{c}\text { Class A } \\
(\mathrm{n}=11)\end{array}$ & $81 \%$ & $16 \%$ & $95 \%$ & $72 \%$ & $28 \%$ & $91 \%$ \\
$\begin{array}{c}\text { Class B } \\
(\mathrm{n}=16)\end{array}$ & $72 \%$ & $27 \%$ & $90 \%$ & $41 \%$ & $56 \%$ & $80 \%$ \\
\hline
\end{tabular}

Table 1 shows that Class B students solved a higher share of tasks by $D F S$ than their peers from Class A did. This pertains particularly to tasks with sums and minuends greater than ten (56\% DFS in B compared to $28 \%$ in A). Along with this, the share of fact mastery was lower in B (80\% for sums and minuends greater 10) than in A (91\% for these "harder facts"). The joint occurrence of a still relatively high share of fact mastery and a more than $50 \%$ share of DFS in Class B indicates that Class B students were generally rather fast in deriving. However, in addition to Table 1, it is important to note that in Class B 22 out of 352 trials $(6.3 \%)$ took ten or more seconds. Six out of 16 children in this class needed that long on more than one task. Conversely, in Class A only two out of 242 solutions $(0.8 \%)$ took that long.

There were no such differences between the classes regarding the helping facts. Table 2 shows that the share of automaticity in solving these tasks was (almost) $100 \%$ in both classes.

\section{Additional Observations}

In both classes, students evidently were experienced and, for the most part, proficient in explaining their solution pathways during the computation part of the interviews. In solving the additional tasks (see above), no child in either class had any problem in verbalizing how $7+8$ relates to $7+7$ (e.g., "in $7+8$ you add one more, so the outcome is one more"). Only about $45 \%$ of both classes alike explained the relation between 18-9 and 9+9 equally adequately (e.g., "18 consists of two nines, so if you take away one nine, the other remains"). 



Australian Association of Mathematics Teachers (pp. 201-207). Adelaide, Australia: AAMT and MERGA.

Cumming, J. J., \& Elkins, J. (1999). Lack of automaticity in the basic addition facts as a characteristic of arithmetic learning problems and instructional needs. Mathematical Cognition, 5(2), 149-180.

Dowker, A. (2014). Young children's use of derived fact strategies for addition and subtraction. Frontiers in Human Neuroscience, 7(924), DOI 10.3389/fnhum.2013.00924.

Edelson, D. C. (2006). Balancing innovation and risk. Assessing design research proposals. In J. van den Akker, K. Gravemeijer, S. McKenney, \& N. Nieveen (Eds.), Educational design research (pp. 100-106). London, UK: Routledge.

Freudenthal, H. (1973). Mathematics as an educational task. Dordrecht, The Netherlands: Springer.

Gaidoschik, M. (2007). Rechenschwäche vorbeugen. Erstes Schuljahr. Vom Zählen zum Rechnen. Wien: G+G.

Gaidoschik, M. (2012). First-graders' development of calculation strategies: How deriving facts helps automatize facts. Journal für MathematikDidaktik, 33(2), 287-315.

Gaidoschik, M., Fellmann, A., Guggenbichler, S., \& Thomas, A. (2017). Empirische Befunde zum Lehren und Lernen auf Basis einer Fortbildungsmaßnahme zur Förderung nicht-zählenden Rechnens. Journal für Mathematik-Didaktik, 37(1), 93-124.

Gerster, H. D. (2009). Schwierigkeiten bei der Entwicklung arithmetischer Konzepte im Zahlenraum bis 100. In A. Fritz, G. Ricken \& S. Schmidt (Eds.), Rechenschwäche. Lernwege, Schwierigkeiten und Hilfen bei Dyskalkulie (pp. 248-268). Weinheim, Germany: Beltz.

Henry, V. J., \& Brown, R. S. (2008). First-grade basic facts: An investigation into teaching and learning of an accelerated, high-demanding memorization standard. Journal for Research in Mathematics Education, 39(2), 153-183.

NCTM (n.d.). Common core state standards for mathematics. Retrieved from http://www.corestandards.org/wpcontent/uploads/Math_Standards1.pdf

Schipper, W. (2009). Handbuch für den Mathematikunterricht an Grundschulen. Braunschweig, Germany: Schroedel.

Schipper, W., Ebeling, A., \& Dröge, R. (2015). Handbuch für den Mathematikunterricht. 1. Schuljahr. Braunschweig, Germany: Bildungshaus Schulbuchverlage.

Steinberg, R. M. (1985). Instruction on derived facts strategies in addition and subtraction. Journal for Research in Mathematics Education, 16(5), 337-355.

Van de Walle, J. A. (2004). Elementary and middle school mathematics: Teaching developmentally. Boston, MA: Pearson. 
